\title{
Alcohol and Cognition in the Elderly: A Review
}

\author{
Jee Wook Kim ${ }^{1,2}$, Dong Young Lee ${ }^{3}$, Boung Chul Lee ${ }^{1,2}$, Myung Hun Jung ${ }^{4}$, \\ Hano $\mathrm{Kim}^{5}$, Yong Sung $\mathrm{Choi}^{6}$ and Ihn-Geun Choi ${ }^{1,2} \bowtie$ \\ ${ }^{1}$ Department of Neuropsychiatry, Hallym University Hangang Sacred Heart Hospital, Seoul, Korea \\ ${ }^{2}$ Hallym University Burn Institute, Hallym University, Seoul, Korea \\ ${ }^{3}$ Department of Neuropsychiatry, Seoul National University Hospital, Seoul, Korea \\ ${ }^{4}$ Department of Neuropsychiatry, Hallym University Sacred Heart Hospital, Anyang, Korea \\ ${ }^{5}$ Department of Neuropsychiatry, Keyo Hospital, Uiwang, Korea \\ ${ }^{6}$ Department of Neuropsychiatry, St. Andrew's Neuropsychiatric Hospital, Icheon, Korea
}

Consumption of large amounts of alcohol is known to have negative effects, but consumption in smaller amounts may be protective. The effect of alcohol may be greater in the elderly than in younger adults, particularly with regard to cognition. However, the drinking pattern that will provide optimal protection against dementia and cognitive decline in the elderly has not been systematically investigated. The present paper is a critical review of research on the effect of alcohol on cognitive function and dementia in the elderly. Studies published from 1971 to 2011 related to alcohol and cognition in the elderly were reviewed using a PubMed search. Alcohol may have both a neurotoxic and neuroprotective effect. Longitudinal and brain imaging studies in the elderly show that excessive alcohol consumption may increase the risk of cognitive dysfunction and dementia, but low to moderate alcohol intake may protect against cognitive decline and dementia and provide cardiovascular benefits. Evidence suggesting that low to moderate alcohol consumption in the elderly protects against cognitive decline and dementia exists; however, because of varying methodology and a lack of standardized definitions, these findings should be interpreted with caution. It is important to conduct more, well-designed studies to identify the alcohol drinking pattern that will optimally protect the elderly against cognitive decline and dementia.

Psychiatry Investig 2012;9:8-16

Key Words Alcohol, Cognition, Neuroprotection, Neurotoxicity, Elderly, Dementia.

\section{INTRODUCTION}

Consumption of large amounts of alcohol is known to have negative effects, but drinking smaller amounts may have a protective effect in adults of all ages. Since alcohol is distributed in body water, a given dose of alcohol will have a greater pharmacokinetic effects in the elderly because of their diminished body water compared to younger adults. ${ }^{1}$ Elderly show markedly consistent pharmacodynamic profile reflecting early peak impairment and rapid acute tolerance, ${ }^{2}$ in conjunction with less pharmacodynamic sensitivity. ${ }^{3}$ These suggest that alcohol consumption may have a greater affect on the elderly than on younger adults, particularly in relation

Received: June 5, 2011 Revised: July 17, 2011

Accepted: August 1, 2011 Available online: January 17, 2012

$\triangle$ Correspondence: Ihn-Geun Choi, MD, PhD

Department of Neuropsychiatry, Hallym University Hangang Sacred Heart Hospital, 94-200 Yeongdeungpo-dong, Yeongdeungpo-gu, Seoul, 150-719 Korea

Tel: +82-2-2639-5461, Fax: +82-2-2677-9095, E-mail: ihngeun@naver.com

(a) This is an Open Access article distributed under the terms of the Creative Commons Attribution Non-Commercial License (http://creativecommons.org/licenses/bync/3.0) which permits unrestricted non-commercial use, distribution, and reproduction in any medium, provided the original work is properly cited. to cognitive function. ${ }^{1}$ However, the systemized reviewed literatures concerning the optimum pattern of alcohol consumption to protect against dementia and cognitive decline in the elderly have been relatively lacking.

The influence of alcohol on health varies depending on the amount consumed, drinking duration, type of alcohol and frequency, environmental factors, and the genetic disposition of the individual. Low to moderate drinking (LMD) may be helpful for stress relief, relaxation, mood elevation, intimacy formation, and cognitive function. ${ }^{4-7}$ Furthermore, LMD may decrease the risk of cardiovascular disease (CVD), respiratory disease, stroke, and mortality. ${ }^{8-10}$ However, frequent heavy drinking or binge drinking may cause CVD, cancer and early death and is associated with alcohol abuse, intoxication, alcohol withdrawal, alcohol withdrawal delirium, alcohol dependence, alcohol-related cognitive impairment, and alcohol-related dementia (ARD), which may lead to severe social, economic, physical, and psychological burdens. ${ }^{11-14}$ Moreover, excessive alcohol consumption may induce organic changes in the region of the frontal cortex primarily involved in cognition and inhibitory control; thus, the relationship between 
alcohol, cognition, and changes in frontal cortex structure have recently become the focus of clinical and neurobiological interest. ${ }^{12,15-17}$

During the normal ageing process, deficits in frontal cortex function (including working memory, speed of information processing, decision-making, planning, and judgment) or retrieval of stored memory may appear, and the decline of semantic memory and verbal or crystallized intelligence is not clear. ${ }^{18}$ In addition to the effects of the normal aging process, the risk or prevalence of mild cognitive impairment and dementia appears to increase with age in the elderly. ${ }^{12,19,20}$ At present, no cure for dementia or therapeutic strategy to prevent the transition of mild cognitive impairment to dementia exist, but epidemiological evidence supports the hypothesis that a healthy lifestyle may prevent the development dementia in the elderly. ${ }^{18,21,22}$ Healthy life habits associated with a reduction in the risk of dementia are exercise, physical activity, healthy diet, and LMD. ${ }^{23-25}$ The type of alcohol and optimal level of consumption associated with a healthy lifestyle are not well understood, and studies of LMD and health often have methodological limitations, such as confounding effects of gender, racial/cultural differences, and comorbidities such as depression and substance use disorders. Thus, the outcomes of studies related to LMD are controversial and systematic reviews of evidence-based research are necessary.

The present review of evidence-based research may help determine the optimal alcohol drinking pattern to prevent cognitive decline and dementia in the elderly and provide an alternative to existing therapeutic interventions, which have limited effectiveness. Accordingly, the present paper is a review of the literature focusing on the influence of alcohol on cognition and dementia in the elderly. We searched the NCBI PubMed database (available at http://www.ncbi.nlm.nih.gov) within the last 10 years (2001 to 2011) using the key words: alcohol, ethanol, cognition, neuroprotection, neurotoxicity, elderly, mild cognitive impairment, and dementia. In some cases, earlier studies from the reference lists of relevant papers (1971 to 2000) were reviewed.

The authors first reviewed the neurotoxic effects of alcohol in the elderly with a focus on cognitive function and changes to brain structure related to psychiatric symptoms and disorders. We then reviewed the neuroprotective effect of alcohol on cognitive function and related changes to brain structure in the elderly with a focus on the optimal pattern and level of alcohol consumption to prevent cognitive dysfunction.

\section{NEUROTOXIC EFFECT OF ALCOHOL}

\section{Mechanism of alcohol neurotoxicity}

The brain is highly vulnerable to the neurotoxic effects of alcohol, and cognitive disorders may result from brain damage caused by chronic alcohol abuse. ${ }^{26}$ The neurotoxic effects of alcohol that cause cognitive deficits may be mediated directly through damage to brain structures or indirectly through malnutrition, metabolite toxicity, electrolyte imbalance, or accompanying physical illnesses including liver disease and infection. ${ }^{27}$ The direct neurotoxic effect of alcohol is mediated via its action on the NMDA receptors of glutamatergic neurons. Acute alcohol intake exerts an inhibitory effect on NMDA receptors and, thus, induces receptor up-regulation, but when alcohol intake ceases, the up-regulated receptors are no longer inhibited, resulting in an excessive stimulation of NMDA receptors. This, in turn, causes an excessive influx of calcium with cytotoxic effects. ${ }^{26} \mathrm{Glu}$ tamatergic neurons are densely concentrated in the frontal lobes and subcortical areas such as the hippocampus, and these brain regions are particularly vulnerable to excitotoxic effects produced by alcohol intake. ${ }^{26}$ Thiamine deficiency and Korsakoff syndrome resulting from chronic alcohol abuse is an example of indirect alcohol neurotoxicity. Thiamine deficiency causes an excessive release of glutamate which, like alcohol, can exert a neurotoxic effect; in fact, chronic alcohol abuse and thiamine deficiency may have an additive or even synergistic neurotoxic effect. ${ }^{28}$ Studies of amnesia in patients with Korsakoff syndrome have shown that the condition may have an anterograde component with inability to learn new information, and a retrograde component in which the recent memory is more impaired than remote memory, and a confabulation component associated with these memory defects. ${ }^{29}$ The apolipoprotein E (APOE) epsilon 4 allele provides a possible genetic explanation for susceptibility to alcohol-induced neurotoxicity. Research findings suggest that people with the allele have a less effective neural repair mechanism and, thus, are more susceptible to the deleterious effects of alcohol. ${ }^{30,31}$ Elevated serum levels of homocysteine is related to alcoholism, ${ }^{32}$ and leads to increase of glutamatergic neurotransmission via overstimulation of NMDA receptors. ${ }^{33}$ This plays a crucial role in the neurobiology of alcoholism, particularly regarding cognitive impairment, ${ }^{34}$ brain atrophy, ${ }^{35}$ and alcohol withdrawal seizures. ${ }^{36}$ Regarding to alcohol neurotoxicity related to immune system, it is reported that chronic alcohol induces systemic cytokines particularly tumor necrosis factor alpha (TNF $\alpha$ ). TNF $\alpha$ appears to involve potentiation of glutamate excitotoxicity and activates resident microglia inducing neuroinflammation. ${ }^{37}$ There are the recent findings in micoglia and astrocyte function toward neurotoxicity via reactive oxygen species under heavy alcohol consumption. . $^{3-40}$ Taken together, alcohol disruption of cytokines and inflammation contribute in multiple ways to a diversity of alcoholic neurotoxicity.

Other mechanisms that may influence alcohol-related neurotoxcity and cognitive dysfunction are free radical toxicity, acetaldehyde toxicity, modulation of the nicotinic acetylcholine 
receptor, serotonin receptor, dopamine receptor, opioid receptor, and gamma-aminobutyric acid (GABA) receptor, but additional studies are necessary to confirm these findings. ${ }^{41-44}$

\section{Acute effect of heavy drinking on cognition}

The common symptoms of acute alcohol neurotoxicity include cognitive impairment, blackout, and hangover. Heavy or binge drinking commonly causes acute alcohol intoxication, and blackouts may occur without loss of consciousness in this state. ${ }^{45}$ After the intoxication has worn off, headache, dysphoric mood, tremor, fatigue, vomiting, loss of appetite, and diarrhea and gastrointestinal symptoms may persist for a considerable amount of time in the hangover. ${ }^{46}$ Blackouts and hangovers occur prior to alcohol-related cognitive dysfunction and are clinically significant as predictive factors for brain damage that may cause transient cognitive impairment or more permanent cognitive dysfunction. ${ }^{47,48}$

Alcohol intoxication during or after heavy alcohol consumption causes clinically maladaptive behavioral changes and physiological changes that may lead to impaired judgment, memory and attention damage, stupor, or coma. ${ }^{49}$ Impairment in free recall, executive function, and visuospatial function are clearly observed at all ages in the state, and most of these symptoms are reversible after alcohol withdrawal. ${ }^{50,51}$

A blackout may be complete (en-bloc) or partial (fragmentary) depending on the severity of memory impairment, ${ }^{52}$ and is related to impaired episodic memory, a type of memory encoded using spatial and social contexts. ${ }^{53}$ Blackout is most consistently associated with a rapid increase in blood alcohol concentration. However, not all people who drink rapidly and excessively experience blackouts, suggesting that genetic disposition plays a role in determining brain vulnerability to alcohol. Alcohol-related blackouts may disturb the memory stages of encoding, storage, and retrieval (recall, recognition), and cause complete or partial deficits in retrieval. Blackouts may result from damage to the hippocampus which is involved in encoding memory at the cellular level, and antagonization of the N-methyl D-aspartate (NMDA) receptors which are necessary for the induction of long-term potentiation in the hippocampus at the molecular level. ${ }^{54}$

Hangovers from alcohol intoxication are generally the result of binge drinking. Studies investigating the relationship between hangover and cognitive deficits have reported conflicting or negative results. This disparity may be the result of methodological differences involving the definition of hangover, alcohol dose, state (e.g., quality of sleep, mood, and uncontrolled behavior), type of tasks, and time of assessment after alcohol intake. However, recent studies using complex tasks to assess cognitive function when the level of alcohol were 0 found a decline in memory, attention, psychomotor performance, and frontal ex- ecutive function during hangover. Further studies are necessary to verify these effects of hangover on cognition. ${ }^{55}$

\section{Cognitive decline in low to moderate drinking}

Ryback ${ }^{56}$ proposed a continuum of alcohol effects on cognition from light functional deterioration in LMD to serious cognitive deficits in heavy drinkers. Consistent with this hypothesis, early studies found cognitive deficits in abstraction and concept formation in young-to middle-aged men who engaged in social drinking, ${ }^{57,58}$ and two studies in women reported similar results. ${ }^{59,60}$ Two previous studies reported that LMD increased cognitive decline in the elderly, ${ }^{61,62}$ and one longitudinal study reported that LMD increased the risk of Alzheimer's disease. ${ }^{63} \mathrm{~A}$ population-based study suggested that elderly low to moderate drinkers who were APOE epsilon 4 allele carriers were more likely to develop dementia compared with nondrinking and non-carrier counterparts. ${ }^{30}$

\section{Effect of low to moderate alcohol intake on brain structures}

Increased brain shrinkage with a linear increase in ventricle size and sulci width has been reported in middle-aged ${ }^{64}$ and elderly ${ }^{65}$ chronic low to moderate drinkers according to the amount of alcohol consumed. Furthermore, a linear increase in white matter volume and decrease in grey matter volume in the frontal and parietal brain regions has been reported in middle-aged men who were chronic low to moderate drinkers. ${ }^{66}$

\section{Alcohol-Related Dementia in heavy drinking}

The relationship between dementia and alcohol use is complex. Chronic heavy drinking may cause brain damage and give rise to ARD, a form of dementia that is clinically different from Alzheimer's disease and vascular dementia. ${ }^{67}$ The concept of ARD is now recognized as Alcohol-Induced Persisting Dementia in the Diagnostic and Statistical Manual of Mental Disorders (DSM)-IV, and its diagnostic criteria must fulfill conditions such as alcohol-related multiple cognitive deficits that may cause significant impairment in social or occupational functioning, compared with the previous level of functioning. Furthermore, the symptoms cannot occur just during the course of delirium and must persist beyond the usual duration of substance intoxication or withdrawal. ${ }^{49}$ This diagnosis, however, has been made entirely at the discretion of the clinician, and considerable controversy exists as to its clinical validity as a diagnostic entity. ${ }^{68}$

Oslin et al. ${ }^{14}$ suggested that the ARD diagnostic criteria be subdivided into probable $\mathrm{ARD}$, possible $\mathrm{ARD}$, and mixed dementia modeled after the National Institute for Neurological and Communicative Disorders and Stroke and the Alzheimer's Disease and Related Disorder Association (NINCDS/ADRDA) diagnostic criteria for Alzheimer's disease. In a subsequent study, 
Oslin et al. ${ }^{67}$ independently verified the validity of these diagnostic criteria and reported that $24 \%$ of dementia patients had $\mathrm{ARD}$ and $10 \%$ of elderly nursing home residents were diagnosed with ARD. These diagnostic criteria continue to be widely used; however, consensus regarding their usefulness has not been reached, and further research is warranted.

The diagnostic algorithm developed by the authors (JWK and $\mathrm{DYL}$ ) to facilitate the clinical diagnosis of $\mathrm{ARD}^{14}$ contains seven 'yes' or 'no' questions and is described as follows: 1) Is it dementia? (Dementia is defined as a significant deterioration of cognitive function sufficient to interfere with social or occupational functioning. As defined by DSM-IV, ${ }^{49}$ this requires deterioration in memory and in at least one other area of intellectual functioning. Moreover, the cognitive changes cannot be attributable to the presence of delirium or substance-induced intoxication or withdrawal.) 2) Was the clinical diagnosis of dementia made at least 60 days after the last exposure to alcohol? 3) Was there significant alcohol use as defined by a minimum average of 35 standard drinks (SD) per week for men or 28 for women over a period greater than 5 years? [If 'yes', go to question 5 , if 'no' go to question 4] 4) Was there significant alcohol use as defined by an average of 21-34 SD per week for men and 14-27 for women over a period greater than 5 years? 5) Did the period of significant alcohol use occur within 3 years of the initial onset of dementia? [If 'yes', go to question 7, if 'no', go to question 6] 6) Did the period of significant alcohol use occur 3-10 years prior to the initial onset of dementia? 7) Is there more than one cause for the dementia? The diagnostic interpretation of the algorithm is as follows. If the answer to questions $1,2,3,5$ is 'yes', the diagnosis is probable ARD. If the answer is 'yes' to questions 1,2 , 3,6 or to $1,2,4,5$, the diagnosis is possible ARD. Finally, if the answer to questions 1 and 7 are 'yes', mixed dementia is diagnosed. A diagnosis of ARD is supported by the presence of any of the following: 1) alcohol-related hepatic, pancreatic, gastrointestinal, cardiovascular, or renal disease, or other end-organ damage; 2) ataxia or peripheral sensory polyneuropathy (not contributable to other specific causes); 3) the cognitive impairment stabilizes or improves after 60 days of abstinence; 4) neuroimaging evidence of ventricular or sulcal dilatation improves after 60 days of abstinence; 5) neuroimaging evidence of cerebellar atrophy, particularly in the vermis. ${ }^{14,67}$

Several recent cohort and epidemiological studies using varying diagnostic criteria in people over 65 years of age have reported a high incidence of comorbid excessive alcohol intake and dementia or the increased risk of dementia and severe cognitive impairment. ${ }^{67,69-72}$ In people diagnosed with ARD, the cognitive deficit manifests as poor working memory, decreased verbal fluency, perseveration, circumstantiality, impaired abstraction, and decreased behavioral initiation, ${ }^{73}$ and magnetic resonance imaging (MRI) scans show ventricular enlargement and diffuse at- rophy disproportionately affecting the prefrontal regions..$^{74,75}$ These neuropsychological deficits and brain damage may be partially reversed with continued abstinence. ${ }^{76-78}$

\section{Marchiafava-Bignami disease in heavy drinking}

Marchiafava-Bignami disease (MBD) is a rare toxic disease commonly found in chronic alcoholics. The exact cause is not known, but progressive demyelination of the corpus callosum is the pathological hallmark of this condition and anatomical pathology examination reveals demyelination and necrosis of the corpus callosum. ${ }^{79}$ Clinically, this disease may start with stupor or coma. Upon recovery, seizure, dementia with complex attention deficits, memory and language difficulty, personality change, and signs of interhemispheric disconnection (e.g., lefthand anomia, apraxia, agraphia) may appear. ${ }^{80,81}$

\section{NEUROPROTECTIVE EFFECT OF ALCOHOL}

\section{Mechanism of alcohol neuroprotection}

Several studies showing a lower risk of CVD in LMD compared with non-drinkers or heavy drinkers suggest a neuroprotective effect of alcohol. ${ }^{82,83}$ This cardioprotection has been attributed, in part, to an alcohol-induced elevation of high density lipoprotein cholesterol (HDL-cholesterol), ${ }^{84}$ reduction of fibrinogen and other thrombotic factors, ${ }^{85-87}$ and reduction in the inflammatory marker C-reactive. ${ }^{88}$ Furthermore, work in animals has shown that the neuroprotective effect is linked to interactions between alcohol and protein kinase $\mathrm{C}$, the adenosine receptor, and cardioprotective proteins (e.g., superoxide dismutase, nitric oxide synthase, and heat shock protein). Moreover, the findings indicated that neuroprotection is correlated with the down-regulation of inducible nitric synthase and up-regulation of endothelial nitric oxide synthase. ${ }^{86}$ Furthermore, a study in animals showed that ingestion of low to moderate levels of alcohol prior ischemic stroke protected against ischemia-induced brain damage by delaying neuronal death, neuronal and dendritic degeneration, oxidative DNA damage, glial cell activation, and neutrophil infiltration. ${ }^{89}$ In addition to the antioxidant properties of alcohol itself, the antioxidant effect of polyphenols (such as resveratrol), which are abundant in red wine, has been proposed to be neuroprotective. ${ }^{90-92}$ Moreover, low to moderate alcohol intake has been shown to act on cholinergic fibers in rats to stimulate prefrontocortical acetylcholine release..$^{93}$

The evidence strongly suggests that LMD acts via these neuroprotective mechanisms and benefits the brain and cardiovascular system by protecting against myocardial infarction, ischemic stroke, cognitive decline, vascular dementia, and Alzheimer's disease. ${ }^{94}$ 


\section{Effect of low to moderate alcohol consumption on cognition}

Studies of the influence of LMD on cognition have reported varying results. Several earlier studies suggested that LMD did not decrease the risk of cognitive decline, including dementia; ${ }^{95-98}$ however, most of those studies had methodological limitations, such as cross-sectional design, small sample size, uncontrolled confounding factors, and variability in age, gender, and type of alcohol. Furthermore, LMD may be a proxy marker that reflects psychiatric and physical health and socio-economical position, and may be related to cognitive functions other than the mechanism that improves the vascular system described above, ${ }^{99}$ thus, caution is required in the evaluation of the relationship between alcohol consumption and cognition.

An increasing number of reports suggest a U- or J-shaped relationship between cognitive function and amount of alcohol consumption, suggesting that LMD is more beneficial to cognition than non-drinking or heavy drinking. ${ }^{65,100-102}$ In contrast, several studies have reported limited or condition-specific benefits of alcohol on cognitive function. Launer et al..$^{103}$ found that alcohol improved cognitive function only in patients with CVD or diabetes mellitus, while other studies have reported a benefit in elderly women, but not men. ${ }^{104,105}$ Studies of the neuroprotective effect of the APOE epsilon 4 allele have reported neuroprotection in the presence of the allele, ${ }^{100,106}$ in the absence of the allele, ${ }^{94,107}$ and no effect in either its presence or absence. ${ }^{6,108}$

In recent cross-sectional population-based studies of African Americans, ${ }^{70}$ French men and women, ${ }^{105}$ Japanese American, ${ }^{109} \mathrm{LMD}$ was found to have a greater cognitive benefit than non-drinking. Moreover, six large-scale longitudinal population-based studies reported similar results. ${ }^{6,108,110-113}$ According to a recent meta-analysis of 23 longitudinal studies (20 epidemiology cohort studies and three retrospective matched casecontrols nested in a cohort) of alcohol consumption and cognitive decline or dementia in elderly people over 65 years of age, LMD significantly reduced the risk of dementia [risk ratio (RR) 0.63 ; 95\% CI 0.53-0.75] and Alzheimer's disease (RR 0.57; 0.440.74 ) and showed a non-significant trend in reducing vascular dementia (RR 0.82; 0.50-1.35) and cognitive decline (RR 0.89; $0.67-1.17) \cdot{ }^{114}$

\section{Effect of low to moderate alcohol intake on brain structures}

MRI results have revealed that chronic LMD may cause brain shrinkage, ${ }^{64,65}$ an increase in white matter volume, and a reduction in grey matter volume; ${ }^{66}$ however, a recent study has reported partially conflicting results showing less white matter damage in elderly low to moderate drinkers compared with nondrinkers. ${ }^{26}$ Furthermore, a U- or J-shaped relationship between alcohol consumption and an increase in brain volume was found in elderly women who were light drinkers ( $<7 \mathrm{SD}$ per week) relative to abstainers. ${ }^{115}$ Two studies reported no change in white and grey matter volume as a function of amount of alcohol consumed in middle-aged women relative to middle-aged men. ${ }^{66,116}$ These gender differences can be explained by the protective effect of estrogen against glutamate toxicity. ${ }^{66}$ Elderly men who were low to moderate drinkers showed a reduction in white matter hyperintensity and an increase in grey matter volume in a U- or J-shaped pattern when compared with abstainers, and elderly women showed no change in either white or grey matter. ${ }^{115}$ Studies of white matter grade, which evaluate the degree of cortical white matter integrity, have reported no significant neuroprotective effect of LMD on white matter grade in men and women (middle-aged adults and older adults of 60-64years old) under 65 years of age. ${ }^{64,115}$ However, a U- or J-shaped pattern between white matter grade and alcohol consumption has been reported in elderly LMDs over 65 years of age. ${ }^{65,117}$ Although studies of the relationship between LMD and changes in brain structure show varying results, overall, the evidence suggests that alcohol has a neuroprotective effect in the elderly. ${ }^{26}$

\section{Optimal alcohol consumption and type}

The size and amount of alcohol contained in a SD differs from country to country, and no standard definition of LMD exists; thus, studies examining the cognitive benefits of LMD often have varying results. It is, therefore, critical that $\mathrm{LMD}$ and $\mathrm{SD}$ be standardized for future studies.

A recent systematic review using a meta-analysis to investigate optimal alcohol consumption to prevent cognitive decline in the elderly found no agreement on the optimal drinking pattern because the classification of LMD varied widely. ${ }^{114}$ Reports of the optimal consumption against cognitive decline in the elderly ranged from more than, less than, or equal to one drink a month ${ }^{113}$ or one drink a day, ${ }^{118}$ and one to two drinks per week in subjects with CVD or diabetes. ${ }^{103}$ The optimal amount reported against Alzheimer's disease was weekly consumption of wine, ${ }^{119}$ one to six or more than two drinks per week, ${ }^{94,120}$ or more than three drinks/250-500 mL per day (usually wine), ${ }^{121}$ or when studied by gender, one to three drinks per day in men..$^{100,120,121}$ Against dementia, benefit was shown with more than one drink per day, weekly, or monthly wine consumption, $250-500 \mathrm{~mL}$ (usually wine) or more than three drinks per day ${ }^{118,120-122}$ and from 1-28 units per week. ${ }^{123}$ One to three drinks per day appeared to be beneficial for men against vascular dementia. ${ }^{100}$

With regard to the alcohol type, the review of longitudinal studies on the influence of alcohol on cognitive function showed that there are mainly reports of cognitive benefit in wine, ${ }^{121,122}$ and there are reports of cognitive benefit regardless of alcohol type. ${ }^{6,94,108}$ 


\section{CONCLUSIONS}

Heavy or binge drinking has neurotoxic effects regardless of age. Alcohol consumption may have a greater affect on the elderly via its pharmacological effects and ageing process than on younger adults, particularly in relation to cognitive function.

Longitudinal and brain imaging studies in the elderly show that excessive alcohol consumption may increase the risk of cognitive dysfunction and dementia, but LMD may protect against cognitive decline and dementia and provide cardiovascular benefits. Evidence suggesting that LMD in the elderly protects against cognitive decline and dementia exists. The present review of evidence-based research may help determine the optimal alcohol drinking pattern to prevent cognitive decline and dementia in the elderly and provide an alternative to existing therapeutic interventions, which have limited effectiveness. However, the varying results of several evidence-based studies of the benefits and risks of alcohol on cognition should be interpreted with caution. Furthermore, the cognitive benefit of LMD may vary from person to person; thus, it is difficult to make a clinical recommendation for abstainers to drink alcohol. Nevertheless, it is important to conduct well-designed studies to determine the optimal alcohol drinking pattern for the elderly as the alternative against cognitive decline and dementia.

\section{Acknowledgments}

This study was supported by a grant of the Korea Healthcare technology R\&D Project, Ministry for Health, Welfare and Family Affairs, Republic of Korea (grant number A084589).

\section{REFERENCES}

1. Dufour M, Fuller RK. Alcohol in the elderly. Annu Rev Med 1995;46: 123-132.

2. Bennett RH, Cherek DR, Spiga R. Acute and chronic alcohol tolerance in humans: effects of dose and consecutive days of exposure. Alcohol Clin Exp Res 1993;17:740-745.

3. Tupler LA, Hege S, Ellinwood EH Jr. Alcohol pharmacodynamics in young-elderly adults contrasted with young and middle-aged subjects. Psychopharmacology (Berl) 1995;118:460-470.

4. Levenson RW, Sher KJ, Grossman LM, Newman J, Newlin DB. Alcohol and stress response dampening: pharmacological effects, expectancy, and tension reduction. J Abnorm Psychol 1980;89:528-538.

5. Lang I, Wallace RB, Huppert FA, Melzer D. Moderate alcohol consumption in older adults is associated with better cognition and wellbeing than abstinence. Age Ageing 2007;36:256-261.

6. Stampfer MJ, Kang JH, Chen J, Cherry R, Grodstein F. Effects of moderate alcohol consumption on cognitive function in women. $\mathrm{N}$ Engl J Med 2005;352:245-253.

7. Baum-Baicker C. The psychological benefits of moderate alcohol consumption: a review of the literature. Drug Alcohol Depend 1985;15:305322.

8. Doll R, Peto R, Boreham J, Sutherland I. Mortality in relation to alcohol consumption: a prospective study among male British doctors. Int J Epidemiol 2005;34:199-204.

9. Klatsky AL, Friedman GD. Alcohol and longevity. Am J Public Health 1995;85:16-18.
10. Reynolds K, Lewis B, Nolen JD, Kinney GL, Sathya B, He J. Alcohol consumption and risk of stroke: a meta-analysis. JAMA 2003;289:579588.

11. Room R, Babor T, Rehm J. Alcohol and public health. Lancet 2005; 365:519-530.

12. Panza F, Capurso C, D'Introno A, Colacicco AM, Frisardi V, Lorusso $\mathrm{M}$, et al. Alcohol drinking, cognitive functions in older age, predementia, and dementia syndromes. J Alzheimers Dis 2009;17:7-31.

13. Fichter MM, Quadflieg N, Fischer UC. Severity of alcohol-related problems and mortality: results from a 20-year prospective epidemiological community study. Eur Arch Psychiatry Clin Neurosci 2011;261: 293-302.

14. Oslin D, Atkinson RM, Smith DM, Hendrie H. Alcohol related dementia: proposed clinical criteria. Int J Geriatr Psychiatry 1998;13:203-212.

15. Perry JL, Joseph JE, Jiang Y, Zimmerman RS, Kelly TH, Darna M, et al. Prefrontal cortex and drug abuse vulnerability: translation to prevention and treatment interventions. Brain Res Rev 2011;65:124-149.

16. Brust JC. Ethanol and cognition: indirect effects, neurotoxicity and neuroprotection: a review. Int J Environ Res Public Health 2010;7:1540-1557.

17. Abernathy K, Chandler LJ, Woodward JJ. Alcohol and the prefrontal cortex. Int Rev Neurobiol 2010;91:289-320.

18. Solfrizzi V, Capurso C, D'Introno A, Colacicco AM, Santamato A, Ranieri $\mathrm{M}$, et al. Lifestyle-related factors in predementia and dementia syndromes. Expert Rev Neurother 2008;8:133-158.

19. Qiu C, De RonchiL D, Fratiglioni L. The epidemiology of the dementias: an update. Curr Opin Psychiatry 2007;20:380-385.

20. Petersen RC, Smith GE, Waring SC, Ivnik RJ, Tangalos EG, Kokmen E. Mild cognitive impairment: clinical characterization and outcome. Arch Neurol 1999;56:303-308.

21. Christensen $H$. What cognitive changes can be expected with normal ageing? Aust N Z J Psychiatry 2001;35:768-775.

22. Solfrizzi V, Colacicco AM, D’Introno A, Capurso C, Parigi AD, Capurso SA, et al. Macronutrients, aluminium from drinking water and foods, and other metals in cognitive decline and dementia. J Alzheimers Dis 2006;10:303-330.

23. Fratiglioni L, Paillard-Borg S, Winblad B. An active and socially integrated lifestyle in late life might protect against dementia. Lancet Neurol 2004;3:343-353.

24. Panza F, Solfrizzi V, Colacicco AM, D’Introno A, Capurso C, Torres F, et al. Mediterranean diet and cognitive decline. Public Health Nutr 2004; 7:959-963.

25. Pinder RM, Sandler M. Alcohol, wine and mental health: focus on dementia and stroke. J Psychopharmacol 2004;18:449-456.

26. Verbaten MN. Chronic effects of low to moderate alcohol consumption on structural and functional properties of the brain: beneficial or not? Hum Psychopharmacol 2009;24:199-205.

27. Neiman J. Alcohol as a risk factor for brain damage: neurologic aspects. Alcohol Clin Exp Res 1998;22:346S-351S.

28. Robinson JK, Mair RG. MK-801 prevents brain lesions and delayednonmatching-to-sample deficits produced by pyrithiamine-induced encephalopathy in rats. Behav Neurosci 1992;106:623-633.

29. Kopelman MD, Thomson AD, Guerrini I, Marshall EJ. The Korsakoff syndrome: clinical aspects, psychology and treatment. Alcohol Alcohol 2009;44:148-154.

30. Anttila T, Helkala EL, Viitanen M, Kareholt I, Fratiglioni L, Winblad B, et al. Alcohol drinking in middle age and subsequent risk of mild cognitive impairment and dementia in old age: a prospective population based study. BMJ 2004;329:539.

31. Mahley RW, Rall SC Jr. Is epsilon4 the ancestral human apoE allele? Neurobiol Aging 1999;20:429-430.

32. Bleich S, Carl M, Bayerlein K, Reulbach U, Biermann T, Hillemacher T, et al. Evidence of increased homocysteine levels in alcoholism: the Franconian alcoholism research studies (FARS). Alcohol Clin Exp Res 2005; 29:334-336.

33. Bleich S, Degner D, Sperling W, Bonsch D, Thurauf N, Kornhuber J. Ho- 
mocysteine as a neurotoxin in chronic alcoholism. Prog Neuropsychopharmacol Biol Psychiatry 2004;28:453-464.

34. Wilhelm J, Bayerlein K, Hillemacher T, Reulbach U, Frieling H, Kromolan B, et al. Short-term cognition deficits during early alcohol withdrawal are associated with elevated plasma homocysteine levels in patients with alcoholism. J Neural Transm 2006;113:357-363.

35. Bleich S, Bandelow B, Javaheripour K, Muller A, Degner D, Wilhelm J, et al. Hyperhomocysteinemia as a new risk factor for brain shrinkage in patients with alcoholism. Neurosci Lett 2003;335:179-182.

36. Bleich S, Bayerlein K, Hillemacher T, Degner D, Kornhuber J, Frieling H. An assessment of the potential value of elevated homocysteine in predicting alcohol-withdrawal seizures. Epilepsia 2006;47:934-938.

37. Crews FT, Bechara R, Brown LA, Guidot DM, Mandrekar P, Oak S, et al. Cytokines and alcohol. Alcohol Clin Exp Res 2006;30:720-730.

38. Gonzalez A, Salido GM. Ethanol alters the physiology of neuron-glia communication. Int Rev Neurobiol 2009;88:167-198.

39. Boyadjieva NI, Sarkar DK. Role of microglia in ethanol's apoptotic action on hypothalamic neuronal cells in primary cultures. Alcohol Clin Exp Res 2010;34:1835-1842.

40. Sullivan EV, Zahr NM. Neuroinflammation as a neurotoxic mechanism in alcoholism: commentary on "Increased MCP-1 and microglia in various regions of human alcoholic brain". Exp Neurol 2008;213:10-17.

41. Deitrich RA, Dunwiddie TV, Harris RA, Erwin VG. Mechanism of action of ethanol: initial central nervous system actions. Pharmacol Rev 1989;41:489-537.

42. Haddad JJ. Alcoholism and neuro-immune-endocrine interactions: physiochemical aspects. Biochem Biophys Res Commun 2004;323:361371.

43. Harper C, Matsumoto I. Ethanol and brain damage. Curr Opin Pharmacol 2005;5:73-78.

44. Kumar S, Porcu P, Werner DF, Matthews DB, Diaz-Granados JL, Helfand RS, et al. The role of GABA(A) receptors in the acute and chronic effects of ethanol: a decade of progress. Psychopharmacology (Berl) 2009; 205:529-564.

45. White AM, Signer ML, Kraus CL, Swartzwelder HS. Experiential aspects of alcohol-induced blackouts among college students. Am J Drug Alcohol Abuse 2004;30:205-224.

46. Stephens R, Ling J, Heffernan TM, Heather N, Jones K. A review of the literature on the cognitive effects of alcohol hangover. Alcohol Alcohol 2008;43:163-170.

47. Read JP, Merrill JE, Kahler CW, Strong DR. Predicting functional outcomes among college drinkers: reliability and predictive validity of the Young Adult Alcohol Consequences Questionnaire. Addict Behav 2007; 32:2597-2610

48. Newlin DB, Pretorius MB. Sons of alcoholics report greater hangover symptoms than sons of nonalcoholics: a pilot study. Alcohol Clin Exp Res 1990;14:713-716.

49. American Psychiatric Association. Task Force on DSM-IV. Diagnostic and Statistical Manual of Mental Disorders: DSM-IV-TR. Washington, DC: American Psychiatric Association; 2000.

50. Brandt J, Butters N, Ryan C, Bayog R. Cognitive loss and recovery in longterm alcohol abusers. Arch Gen Psychiatry 1983;40:435-442.

51. Grant I. Alcohol and the brain: neuropsychological correlates. J Consult Clin Psychol 1987;55:310-324.

52. Hartzler B, Fromme K. Fragmentary and en bloc blackouts: similarity and distinction among episodes of alcohol-induced memory loss. J Stud Alcohol 2003;64:547-550.

53. White AM. What happened? Alcohol, memory blackouts, and the brain. Alcohol Res Health 2003;27:186-196.

54. Lee H, Roh S, Kim DJ. Alcohol-induced blackout. Int J Environ Res Public Health 2009;6:2783-2792.

55. Prat G, Adan A, Perez-Pamies M, Sanchez-Turet M. Neurocognitive effects of alcohol hangover. Addict Behav 2008;33:15-23.

56. Ryback RS. The continuum and specificity of the effects of alcohol on memory. A review. Q J Stud Alcohol 1971;32:995-1016.
57. Parker ES, Noble EP. Alcohol and the aging process in social drinkers. J Stud Alcohol 1980;41:170-178.

58. Parker ES, Parker DA, Brody JA, Schoenberg R. Cognitive patterns resembling premature aging in male social drinkers. Alcohol Clin Exp Res 1982;6:46-52.

59. Parker DA, Parker ES, Brody JA, Schoenberg R. Alcohol use and cognitive loss among employed men and women. Am J Public Health 1983;73: 521-526.

60. Parker ES, Parker DA, Harford TC. Specifying the relationship between alcohol use and cognitive loss: the effects of frequency of consumption and psychological distress. J Stud Alcohol 1991;52:366-373.

61. Zhou H, Deng J, Li J, Wang Y, Zhang M, He H. Study of the relationship between cigarette smoking, alcohol drinking and cognitive impairment among elderly people in China. Age Ageing 2003;32:205-210.

62. Jarvenpaa T, Rinne JO, Koskenvuo M, Raiha I, Kaprio J. Binge drinking in midlife and dementia risk. Epidemiology 2005;16:766-771.

63. Leibovici D, Ritchie K, Ledesert B, Touchon J. The effects of wine and tobacco consumption on cognitive performance in the elderly: a longitudinal study of relative risk. Int J Epidemiol 1999;28:77-81.

64. Ding J, Eigenbrodt ML, Mosley TH Jr, Hutchinson RG, Folsom AR, Harris TB, et al. Alcohol intake and cerebral abnormalities on magnetic resonance imaging in a community-based population of middle-aged adults: the Atherosclerosis Risk in Communities (ARIC) study. Stroke 2004; 35:16-21.

65. Mukamal KJ, Longstreth WT Jr, Mittleman MA, Crum RM, Siscovick DS. Alcohol consumption and subclinical findings on magnetic resonance imaging of the brain in older adults: the cardiovascular health study. Stroke 2001;32:1939-1946.

66. de Bruin EA, Hulshoff Pol HE, Schnack HG, Janssen J, Bijl S, Evans AC, et al. Focal brain matter differences associated with lifetime alcohol intake and visual attention in male but not in female non-alcohol-dependent drinkers. Neuroimage 2005;26:536-545.

67. Oslin DW, Cary MS. Alcohol-related dementia: validation of diagnostic criteria. Am J Geriatr Psychiatry 2003;11:441-447.

68. Victor M. Persistent altered mentation due to ethanol. Neurol Clin 1993; 11:639-661.

69. Finlayson RE, Hurt RD, Davis LJ Jr, Morse RM. Alcoholism in elderly persons: a study of the psychiatric and psychosocial features of 216 inpatients. Mayo Clin Proc 1988;63:761-768.

70. Hendrie HC, Gao S, Hall KS, Hui SL, Unverzagt FW. The relationship between alcohol consumption, cognitive performance, and daily functioning in an urban sample of older black Americans. J Am Geriatr Soc 1996;44:1158-1165.

71. Saunders PA, Copeland JR, Dewey ME, Davidson IA, McWilliam C, Sharma V, et al. Heavy drinking as a risk factor for depression and dementia in elderly men. Findings from the Liverpool longitudinal community study. Br J Psychiatry 1991;159:213-216.

72. Thomas VS, Rockwood KJ. Alcohol abuse, cognitive impairment, and mortality among older people. J Am Geriatr Soc 2001;49:415-420.

73. Saxton J, Munro CA, Butters MA, Schramke C, McNeil MA. Alcohol, dementia, and Alzheimer's disease: comparison of neuropsychological profiles. J Geriatr Psychiatry Neurol 2000;13:141-149.

74. Pfefferbaum A, Sullivan EV, Mathalon DH, Lim KO. Frontal lobe volume loss observed with magnetic resonance imaging in older chronic alcoholics. Alcohol Clin Exp Res 1997;21:521-529.

75. Pfefferbaum A, Sullivan EV, Rosenbloom MJ, Mathalon DH, Lim KO. A controlled study of cortical gray matter and ventricular changes in alcoholic men over a 5-year interval. Arch Gen Psychiatry 1998;55:905912.

76. Pfefferbaum A, Sullivan EV, Mathalon DH, Shear PK, Rosenbloom MJ, Lim KO. Longitudinal changes in magnetic resonance imaging brain volumes in abstinent and relapsed alcoholics. Alcohol Clin Exp Res 1995;19:1177-1191.

77. Shear PK, Jernigan TL, Butters N. Volumetric magnetic resonance imaging quantification of longitudinal brain changes in abstinent alcohol- 
ics. Alcohol Clin Exp Res 1994;18:172-176.

78. Joyce EM. Aetiology of alcoholic brain damage: alcoholic neurotoxicity or thiamine malnutrition? Br Med Bull 1994;50:99-114.

79. Fortman BJ, Kuszyk BS. Incidentally diagnosed Marchiafava-Bignami disease. AJR Am J Roentgenol 1999;173:1713-1714.

80. Berek K, Wagner M, Chemelli AP, Aichner F, Benke T. Hemispheric disconnection in Marchiafava-Bignami disease: clinical, neuropsychological and MRI findings. J Neurol Sci 1994;123:2-5.

81. Ferracci F, Conte F, Gentile M, Candeago R, Foscolo L, Bendini M, et al. Marchiafava-Bignami disease: computed tomographic scan, $99 \mathrm{mTc}$ HMPAO-SPECT, and FLAIR MRI findings in a patient with subcortical aphasia, alexia, bilateral agraphia, and left-handed deficit of constructional ability. Arch Neurol 1999;56:107-110.

82. Solomon CG, Hu FB, Stampfer MJ, Colditz GA, Speizer FE, Rimm $\mathrm{EB}$, et al. Moderate alcohol consumption and risk of coronary heart disease among women with type 2 diabetes mellitus. Circulation 2000; 102:494-499.

83. Rimm E. Alcohol and cardiovascular disease. Curr Atheroscler Rep 2000;2:529-535.

84. Mukamal KJ, Jensen MK, Gronbaek M, Stampfer MJ, Manson JE, Pischon T, et al. Drinking frequency, mediating biomarkers, and risk of myocardial infarction in women and men. Circulation 2005;112:14061413.

85. Aikens ML, Grenett HE, Benza RL, Tabengwa EM, Davis CG, Booyse FM. Alcohol-induced upregulation of plasminogen activators and fibrinolytic activity in cultured human endothelial cells. Alcohol Clin Exp Res 1998;22:375-381.

86. Collins MA, Neafsey EJ, Mukamal KJ, Gray MO, Parks DA, Das DK, et al. Alcohol in moderation, cardioprotection, and neuroprotection: epidemiological considerations and mechanistic studies. Alcohol Clin Exp Res 2009;33:206-219.

87. Renaud SC, Ruf JC. Effects of alcohol on platelet functions. Clin Chim Acta 1996;246:77-89.

88. Sierksma A, van der Gaag MS, Kluft C, Hendriks HF. Moderate alcohol consumption reduces plasma C-reactive protein and fibrinogen levels; a randomized, diet-controlled intervention study. Eur J Clin Nutr 2002; 56:1130-1136

89. Wang Q, Sun AY, Simonyi A, Kalogeris TJ, Miller DK, Sun GY, et al. Ethanol preconditioning protects against ischemia/reperfusion-induced brain damage: role of NADPH oxidase-derived ROS. Free Radic Biol Med 2007;43:1048-1060.

90. Das S, Khan N, Mukherjee S, Bagchi D, Gurusamy N, Swartz H, et al. Redox regulation of resveratrol-mediated switching of death signal into survival signal. Free Radic Biol Med 2008;44:82-90.

91. Mokni M, Limam F, Elkahoui S, Amri M, Aouani E. Strong cardioprotective effect of resveratrol, a red wine polyphenol, on isolated rat hearts after ischemia/reperfusion injury. Arch Biochem Biophys 2007;457:1-6.

92. Mokni M, Elkahoui S, Limam F, Amri M, Aouani E. Effect of resveratrol on antioxidant enzyme activities in the brain of healthy rat. Neurochem Res 2007;32:981-987.

93. Stancampiano R, Carta M, Cocco S, Curreli R, Rossetti ZL, Fadda F. Biphasic effects of ethanol on acetylcholine release in the rat prefrontal cortex. Brain Res 2004;997:128-132.

94. Mukamal KJ, Kuller LH, Fitzpatrick AL, Longstreth WT Jr, Mittleman MA, Siscovick DS. Prospective study of alcohol consumption and risk of dementia in older adults. JAMA 2003;289:1405-1413.

95. Dent OF, Sulway MR, Broe GA, Creasey H, Kos SC, Jorm AF, et al. Alcohol consumption and cognitive performance in a random sample of Australian soldiers who served in the Second World War. BMJ 1997;314: 1655-1657.

96. Hebert LE, Scherr PA, Beckett LA, Funkenstein HH, Albert MS, Chown $\mathrm{MJ}$, et al. Relation of smoking and alcohol consumption to incident Alzheimer's disease. Am J Epidemiol 1992;135:347-355.

97. Broe GA, Creasey H, Jorm AF, Bennett HP, Casey B, Waite LM, et al. Health habits and risk of cognitive impairment and dementia in old age: a prospective study on the effects of exercise, smoking and alcohol consumption. Aust N Z J Public Health 1998;22:621-623.

98. Graves AB, van Duijn CM, Chandra V, Fratiglioni L, Heyman A, Jorm $\mathrm{AF}$, et al. Alcohol and tobacco consumption as risk factors for Alzheimer's disease: a collaborative re-analysis of case-control studies. EURODEM Risk Factors Research Group. Int J Epidemiol 1991;20(Suppl 2): S48-S57.

99. Rabbitt P, Donlan C, Watson P, McInnes L, Bent N. Unique and interactive effects of depression, age, socioeconomic advantage, and gender on cognitive performance of normal healthy older people. Psychol Aging 1995;10:307-313.

100. Ruitenberg A, van Swieten JC, Witteman JC, Mehta KM, van Duijn CM, Hofman A, et al. Alcohol consumption and risk of dementia: the Rotterdam Study. Lancet 2002;359:281-286.

101. Zuccala G, Onder G, Pedone C, Cesari M, Landi F, Bernabei R, et al. Dose-related impact of alcohol consumption on cognitive function in advanced age: results of a multicenter survey. Alcohol Clin Exp Res 2001; 25:1743-1748.

102. Kalmijn S, van Boxtel MP, Verschuren MW, Jolles J, Launer LJ. Cigarette smoking and alcohol consumption in relation to cognitive performance in middle age. Am J Epidemiol 2002;156:936-944.

103. Launer LJ, Feskens EJ, Kalmijn S, Kromhout D. Smoking, drinking, and thinking. The Zutphen Elderly Study. Am J Epidemiol 1996;143:219-227.

104. McGuire LC, Ajani UA, Ford ES. Cognitive functioning in late life: the impact of moderate alcohol consumption. Ann Epidemiol 2007;17:9399.

105. Dufouil C, Ducimetiere P, Alperovitch A. Sex differences in the association between alcohol consumption and cognitive performance. EVA Study Group. Epidemiology of Vascular Aging. Am J Epidemiol 1997;146:405412.

106. Carmelli D, Swan GE, Reed T, Schellenberg GD, Christian JC. The effect of apolipoprotein E epsilon4 in the relationships of smoking and drinking to cognitive function. Neuroepidemiology 1999;18:125-133.

107. Dufouil C, Tzourio C, Brayne C, Berr C, Amouyel P, Alperovitch A. Influence of apolipoprotein $\mathrm{E}$ genotype on the risk of cognitive deterioration in moderate drinkers and smokers. Epidemiology 2000;11:280284.

108. Ngandu T, Helkala EL, Soininen H, Winblad B, Tuomilehto J, Nissinen A, et al. Alcohol drinking and cognitive functions: findings from the Cardiovascular Risk Factors Aging and Dementia (CAIDE) Study. Dement Geriatr Cogn Disord 2007;23:140-149.

109. Bond GE, Burr R, McCurry SM, Graves AB, Larson EB. Alcohol, aging, and cognitive performance in a cohort of Japanese Americans aged 65 and older: the Kame project. Int Psychogeriatr 2001;13:207223.

110. Cervilla JA, Prince M, Joels S, Lovestone S, Mann A. Long-term predictors of cognitive outcome in a cohort of older people with hypertension. Br J Psychiatry 2000;177:66-71.

111. Galanis DJ, Joseph C, Masaki KH, Petrovitch H, Ross GW, White L. A longitudinal study of drinking and cognitive performance in elderly Japanese American men: the Honolulu-Asia Aging Study. Am J Public Health 2000;90:1254-1259.

112. Bond GE, Burr RL, McCurry SM, Rice MM, Borenstein AR, Larson EB. Alcohol and cognitive performance: a longitudinal study of older Japanese Americans. The Kame Project. Int Psychogeriatr 2005;17:653668.

113. Ganguli M, Vander Bilt J, Saxton JA, Shen C, Dodge HH. Alcohol consumption and cognitive function in late life: a longitudinal community study. Neurology 2005;65:1210-1217.

114. Peters R, Peters J, Warner J, Beckett N, Bulpitt C. Alcohol, dementia and cognitive decline in the elderly: a systematic review. Age Ageing 2008; 37:505-512.

115. Anstey KJ, Jorm AF, Reglade-Meslin C, Maller J, Kumar R, von Sanden $\mathrm{C}$, et al. Weekly alcohol consumption, brain atrophy, and white matter hyperintensities in a community-based sample aged 60 to 64 years. 
Psychosom Med 2006;68:778-785.

116. Taki Y, Goto R, Evans A, Zijdenbos A, Neelin P, Lerch J, et al. Voxelbased morphometry of human brain with age and cerebrovascular risk factors. Neurobiol Aging 2004;25:455-463.

117. den Heijer T, Vermeer SE, van Dijk EJ, Prins ND, Koudstaal PJ, van Duijn $\mathrm{CM}$, et al. Alcohol intake in relation to brain magnetic resonance imaging findings in older persons without dementia. Am J Clin Nutr 2004; 80:992-997.

118. Espeland MA, Gu L, Masaki KH, Langer RD, Coker LH, Stefanick ML, et al. Association between reported alcohol intake and cognition: results from the Women's Health Initiative Memory Study. Am J Epidemiol 2005; 161:228-238.

119. Lindsay J, Laurin D, Verreault R, Hebert R, Helliwell B, Hill GB, et al. Risk factors for Alzheimer's disease: a prospective analysis from the Ca- nadian Study of Health and Aging. Am J Epidemiol 2002;156:445-453.

120. Orgogozo JM, Dartigues JF, Lafont S, Letenneur L, Commenges D, Salamon R, et al. Wine consumption and dementia in the elderly: a prospective community study in the Bordeaux area. Rev Neurol (Paris) 1997; 153:185-192.

121. Larrieu S, Letenneur L, Helmer C, Dartigues JF, Barberger-Gateau P. Nutritional factors and risk of incident dementia in the PAQUID longitudinal cohort. J Nutr Health Aging 2004;8:150-154.

122. Truelsen T, Thudium D, Gronbaek M; Copenhagen City Heart Study. Amount and type of alcohol and risk of dementia: the Copenhagen City Heart Study. Neurology 2002;59:1313-1319.

123. Simons LA, Simons J, McCallum J, Friedlander Y. Lifestyle factors and risk of dementia: Dubbo Study of the elderly. Med J Aust 2006;184:68-70. 